\title{
Is There Job Satisfaction \\ in Community Mental Health?
}

\author{
Cary Cherniss, Ph.D.* \\ Edward Egnatios, M.S.W.
}

\begin{abstract}
After discussing the importance of job satisfaction, this paper presents data concerning current levels and sources of job satisfaction in community mental health centers. Data came from a survey completed by 164 staff members working in 22 different programs located in Michigan. The return rate was $94 \%$. Results indicated that compared to workers in other occupations, the staff were about average in satisfaction with co-workers and superoision, but low in satisfaction with the work itself. The two major sources of job satisfaction reported by staff were the level of accomplishment experienced in the work and the degree of clarity in organizational goals and policies. The paper concludes by suggesting ways in which job satisfaction in community mental health could be increased.
\end{abstract}

At a recent national conference attended by community mental health staff from throughout the country, Seymour Sarason of Yale University gave a keynote address in which he focused on the nature of work in community mental health. The picture he painted was a grim one. Community mental health staff begin with the usual expectations for professional work in a helping field: high autonomy, challenging and interesting work, and the sense that one has helped others in a significant way. Instead they find themselves locked into a rigid, increasingly oppressive bureaucracy, constantly confronted with red tape and confining regulations, and asked to perform many different, conflicting tasks for which they were never adequately trained. Not only did Sarason's address receive an ovation, but during the next 2 days, conference participants continually referred to it in their workshop and discussions. Most seemed to feel that he had uncovered a problem experienced by all, frequently discussed in informal gatherings during work breaks and after hours, but rarely a topic in public pronouncements about community mental health and its current state.

But why should the quality of work in community mental health become a major social policy issue?

First, satisfying, meaningful, and interesting work is increasingly being seen as a "right" for blue-collar and white-collar workers in our society. It should be considered a right of those occupied in helping professions.

Second, there usually is a strong relationship between job satisfaction and

${ }^{*} \mathrm{Dr}$. Cherniss is connected with the Department of Psychology, University of Michigan, 529 Thompson Street, Ann Arbor, Michigan 48109. Research for this paper was made possible through a special grant from Professor Seymour B. Sarason of Yale University. The authors would like to thank Professor Sarason for his continuing encouragement and support, and also Beatrice Bonneoaux for her assistance on the data analysis. 
work motivation. In some types of work (for example, assembly-line work), worker motivation probably is not as critical. The assembly line continues to move, the workers continue to perform their simple tasks, and those who are highly motivated will probably do about as much and as well as those who are not (if the workers are watched closely enough). However, in work such as psychotherapy, counseling, and mental health consultation, the worker's motivation probably influences performance in substantial ways. Several previous studies have suggested a relationship between staff morale, staff performance, and client outcomes (Frank, 1973; Schwartz \& Will, 1961; Stotland \& Kobler, 1965).

Third, lower staff morale may lead to increases in turnover, absenteeism, and staff conflict. Even state auditors of mental health programs have become concerned about staff turnover and its social as well as economic costs. One recent state audit of a local mental health program recommended "internal program evaluation to detect reasons for high employee turnover" (Dunn, 1976). Although there are many complex economic factors influencing turnover rates, job satisfaction levels usually make a significant contribution.

Job satisfaction also can influence service delivery in its effect on staff recruitment and hiring. The nation's mental health system today is a complex, multifaceted one in which there are many different institutional segments competing for the available professional resources. Community mental health centers must compete for staff with many other types of agencies and institutions, including universities, private clinics, state hospitals, private practice, and many nonmental health settings which increasingly employ mental health professionals for mental health-related components of their programs. The number of truly gifted and effective helping professionals is still quite limited. The best trained and most effective mental health workers have a choice about where they will work, and usually they will gravitate to those segments of the mental health system where the working conditions are most favorable. The more talented, creative, and compassionate mental health professionals clearly want more than just a good salary. They also value stimulating, meaningful work. If community mental health jobs come to be seen as unfulfilling, the field will become an "employment slum" in the same way that the state hospitals did long ago (Sarason, 1974).

One final reason for concern with job satisfaction in community mental health is unionization. Without a doubt, unionization of public sector professionals has dramatically increased over the last decade (Oppenheimer, 1975). The factors that lead to unionization are numerous and complex, but certainly low job satisfaction plays a role. When unionization is a response to oppressive and frustrating working conditions, it is an understandable and sometimes effective way of improving those conditions. There surely can be little doubt that unionization frequently leads to improvements in areas such as salary and job security. However, unions often become another bureaucracy with which workers must contend (Mills, 1951). In attempting to regulate and improve working conditions through collective bargaining agreements, 
unions sometimes unwittingly impose even more bureaucratic control and rigidity in the work place, reducing rather than increasing the actual autonomy, freedom, and control of the individual worker. Thus unionization that grows out of job dissatisfaction often is a mixed blessing in terms of both working conditions, broadly defined, and the quality of services received by the client.

Despite the importance of job satisfaction in the human services, there has been little research conducted in the area, and none that we know of concerned specifically with community mental health work. Sarata (1972) counted only 19 studies of job satisfaction in "helping occupations" between 1927 and 1969, and many of these studies concerned vocational and rehabilitation counseling, corrections, medical care, and social welfare fields rather than mental health. Also, previous research has been plagued by low response rates (often less than $50 \%$ ) and the absence of standardized measures allowing comparisons to be made between various groups.

Thus in light of the potential importance of job satisfaction and working conditions in community mental health, as well as the paucity of relevant data, we believed it was necessary to conduct research addressing two basic questions: First, compared to other well-educated workers in the labor force, how satisfied are community mental health workers? Second, what aspects of the job are most critical for determining level of satisfaction?

Our first attempt to answer these questions was a pilot study involving 72 line staff working in six different programs associated with a single community mental health center. Using the Job Description Inventory (JDI), a standardized measure of job satisfaction developed by Smith, Kendall, and Hulin (1969), we found that the average staff member placed at the 23 rd percentile in satisfaction with work, the 30th percentile in satisfaction with supervision, and the 29th percentile in satisfaction with co-workers, when compared with the national sample of highly educated workers used in developing the instrument. Thus there was evidence that job satisfaction levels in community mental health were alarmingly low.

We also found that the four major reported sources of frustration and work alienation for the staff were (1) a feeling of inadequacy in performing many activities, especially those for which the staff had received poor training and supervision, such as mental health consultation; (2) a lack of direct and immediate feedback concerning results in many work activities; (3) excessive paperwork; and (4) role conflicts, poorly defined objectives, sudden changes in personnel and rules, the need to consider constantly and deal with "politics," and other organizational issues.

Although the pilot study provided some initial data relevant to the major questions we had about job satisfaction in community mental health, it was limited in three important respects: First, the staff came from a limited number of agencies which were all part of a single, county-wide community mental health program. Second, the response rate was a disappointing $68 \%$. Finally, the limited questionnaire did not measure many critical job and or- 
ganizational dimensions. Thus we could not generalize from the results and a larger, more extensive study seemed to be indicated. The data presented below came from this second study.

\title{
METHOD
}

\begin{abstract}
Subjects
The subjects were 164 line staff members and supervisors employed in 22 different community mental health programs and agencies in Michigan. Six programs were located in predominantly urban areas; three were located in rural areas; and the rest were predominantly suburban. Females slightly outnumbered males ( $54 \%$ vs. $46 \%$ ). Just less than half the sample (46\%) held a graduate degree, and $18 \%$ lacked a bachelor's degree. A large percentage $(26 \%)$ had 1 year or less experience in mental health work while $20 \%$ had worked professionally for at least 7 years. Nine percent indicated that they were black; the rest indicated "white" or refused to say. Of the 160 subjects who indicated a professional affiliation, there were 10 nurses, 2 psychiatrists, 24 psychologists, and 55 social workers. The others were primarily paraprofessional mental health workers, although there also were a small number of teachers, occupational therapists, and other miscellaneous disciplines. Of the 174 staff actually eligible to participate, 164 eventually agreed to do so for a response rate of $94 \%$. Only one program of the 23 contacted about participating refused. Of the 22 programs that did participate, there were 10 counseling agencies, many of which also provided some consultation and education services; 5 day treatment programs serving adults or children; 1 drug abuse program; 1 alcoholism program; 2 emergency services programs; 1 mental retardation program; 1 inpatient program; and 1 program connected with the probate court.
\end{abstract}

\section{Instruments}

Data came from a questionnaire asking for information related to training, duties, working conditions, and attitudes about various aspects of one's work. The following items and scales were used to collect the data presented in this paper.

Job satisfaction level. The three scales of the JDI (Smith, et al., 1969) measuring satisfaction with work, supervision, and co-workers were used to determine relative level of satisfaction with these job facets.

Sources of job satisfaction and dissatisfaction. Questionnaire items asked staff to indicate the three major sources of satisfaction and dissatisfaction in their work. A rater who was naive about previous research findings on job satisfaction developed a set of content categories for grouping the responses after reading them once. She then computed the frequency of responses falling within each category. One of the authors then further combined the original categories into 12 groupings: work load; performance and accomplishment; co-workers; autonomy and power; learning and personal development; order, clarity, and organization; extrinsic rewards; physical comfort and convenience; recognition and respect; supervision; agency performance; and a small miscellaneous category containing responses too vague or general to categorize more precisely. In addition to the categories based on staff responses to the openended items, the questionnaire included a number of specific items concerning work load, salary, sense of accomplishment and visible impact, utilization of skills, perceived social value of one's work, autonomy, role conflict and ambiguity, communication, and future work plans.

\section{Procedure}

All staff providing mental health services and employed at least half time were asked to participate. Staff filled out the questionnaires at their agencies during regular staff meetings after one of the investigators explained the nature of the study to them and answered any questions. The average staff member required $\mathbf{4 0}$ minutes to complete the survey. 


\section{RESULTS}

\section{Job Satisfaction Levels}

The data suggest that community mental health staff are considerably less satisfied with their work than comparable groups of American workers. To determine the relative job satisfaction of the community mental health staff, their mean scores on the JDI were compared with those of the normative samples used to construct the instrument. Because job satisfaction has been found to vary systematically with sex and educational level, the norms from the JDI were stratified on these variables. Thus the corresponding stratifications were made on the community mental health staff with appropriate normative groups: male staff with at least 3 years of college $(n=61)$; male staff with less than 3 years of college $(n=13)$; and female staff $(n=88)$. (Female staff could not be stratified by educational level because the JDI norms include all women workers with more than 8 years of schooling in one category, and all but one of the female community mental health staff in our sample had surpassed this educational level.)

When each of the three community mental health staff groups was compared with the appropriate normative sample, a consistent picture emerged; in each case, the average community mental health staff member scored relatively low in satisfaction with work but close to the median in satisfaction with supervision and co-workers (see Table 1). Thus if there is a "job satisfaction

\section{TABLE 1}

Mean Job Satisfaction Scores for Three Groups of Community Mental Health Staff

\begin{tabular}{lccc}
\hline \multicolumn{1}{c}{ Source } & $\begin{array}{c}\text { As } \\
\text { Satisfaction }\end{array}$ & $\begin{array}{c}\text { As } \\
\text { Dissatisfaction }\end{array}$ & Total \\
\hline 1. A Particular Type of Activity & 151 & 62 & 213 \\
2. Sense of Accomplishment & 97 & 40 & 137 \\
3. Coworkers & 81 & 24 & 105 \\
4. Autonony & 45 & 48 & 93 \\
5. Leaming and Personal Development & 64 & 21 & 85 \\
6. Onganizational Quality & 9 & 70 & 79 \\
7. Extrinsic Rewards & 11 & 65 & 76 \\
8. Comfort and Convenience & 17 & 51 & 51 \\
9. Amount of Work & 2 & 49 & 25 \\
10. Recognition and Respect & 7 & 18 & 22 \\
11. Supervisor & 11 & 11 & 18 \\
12. Agency Performance & 0 & 18 & 11 \\
13. Other (Too general to categorize) & 0 & & \\
\hline
\end{tabular}


problem" in community mental health, it would seem to be associated with work-related aspects of the job rather than with supervision or co-workers.

\section{Relation Between Job Dissatisfaction \\ and Future Work Plans}

One potential negative outcome of job dissatisfaction is a greater desire to seek other jobs in other settings; is this the case for community mental health staff? The relationship between future work plans and current work satisfaction level does support the assumption that job satisfaction influences staff turnover. Those who plan to be working in the same agency 1 year from now $(n=109)$ scored significantly higher on the JDI work satisfaction scale than those $(n=41)$ planning to leave $(t(148)=4.19, p$ $<.0001$ ). Level of satisfaction with supervision or co-workers was not associated with plans for leaving the job and agency in the near future. Thus in community mental health agencies, staff turnover may be more influenced by level of satisfaction with the work itself than with the surrounding "social climate" of the work setting. Further, we have seen that the staff were relatively more dissatisfied on this work dimension than on the supervision or co-workers dimensions of the job. Thus current levels of job satisfaction may be leading to excessively high turnover.

\section{Sense of Accomplishment and}

Its Relation to Satisfaction

Analysis of different types of data from the questionnaire strongly suggests that the primary factor influencing current levels of satisfaction with community mental health work is one's sense of accomplishment, the extent to which staff members feel that they are effectively using their skills to achieve socially worthwhile goals. The first evidence indicating the primary importance of a sense of accomplishment came from analysis of staff responses to the two open-ended questionnaire items asking for the major sources of satisfaction and dissatisfaction in the job. Results of the content analysis, presented in Table 2, indicate that the two types of items cited most often were (1) a particular type of work activity (such as "psychotherapy with adults" or "supervising other staff"), and (2) some statement suggesting a sense of competence, adequacy, or impact in performing one's work role. (The specific subcategories included in this performance category were "client improvement," "sense of accomplishment," "allows creativity," and "social value.")

The specific activities cited as major sources of satisfaction also tended to be those that the staff felt most self-confident in performing. Of the 151 times that a particular activity was cited as a major satisfier in the job, 108 times the activity involved direct counseling or therapy with clients. When staff were asked to rate their own competence in performing a variety of professional activities, they rated their competence in counseling and therapy higher than in any of the other 18 activities presented in the list. More specifically, staff 
TABLE 2

Number of Times Staff Cited Different Sources of Job Satisfaction in Response to Open-Ended Questions

\begin{tabular}{|c|c|c|c|}
\hline $\begin{array}{l}\text { Mal } \\
\text { At Le } \\
\text { of }\end{array}$ & $\begin{array}{l}\text { Staff: } \\
\text { st } 3 \text { Years } \\
\text { College }\end{array}$ & $\begin{array}{c}\text { Male Staff: } \\
\text { Iess than } 3 \\
\text { Years of College }\end{array}$ & $\begin{array}{l}\text { Female } \\
\text { Staff }\end{array}$ \\
\hline Job Facet & $(61)$ & (13) & (88) \\
\hline Work & 21 & 30 & 35 \\
\hline Supervision & 44 & 50 & 44 \\
\hline Coworkers & 47 & 55 & 45 \\
\hline
\end{tabular}

Note. Scores expressed as percentiles, based on comparison with norms from national sample of workers in a variety of occupations. Numbers in parentheses refer to number of staff in group.

self-confidence in counseling and therapy was significantly higher than selfconfidence in mental health consultation $(t(113)=4.91, p<.0001)$ or in community organization $(t(111)=8.24, p<.0001)$. Thus the work activity cited as a satisfier most often is also the activity that staff members feel most confident performing.

One further set of data pointing to the importance of a sense of accomplishment came from direct responses to questionnaire items measuring various job aspects. Table 3 includes correlations between these items and the work satisfaction score from the JDI. The largest single correlation is between the perceived social value of the work and work satisfaction $(r=.46)$. Also high are the correlations for sense of accomplishment $(r=.44)$ and the extent to which one feels the agency's goals are worthwhile $(r=.43)$. All six items measuring achievement aspects of the job (social value, sense of accomplishment, worthiness and attainability of goals, utilization of skills, impact on agency) are significantly correlated with level of satisfaction with work. Thus data from a number of different sources point to the sense of accomplishment as a primary source of work satisfaction for community mental health staff.

Although the sense of accomplishment seems to be the most critical source of satisfaction and fulfillment in work, there clearly are other important ones as well. As Table 2 suggests, the category labeled "organizational quality" proved to be the most frequently cited source of dissatisfaction. (It rarely is seen as a major source of satisfaction.) Specific subcategories included under organizational quality were "poor communication," "lack of organization," "ambiguity," and "inefficiency." Not only did staff mention organizational quality as a major dissatisfier more than any other factor, but also some of the questionnaire items related to this dimension, such as clarity of program goals, ambiguity of role expectations, and adequacy of communication in 
TABLE 3

Correlations Between Aspects of Work and Work Satisfaction Level

\begin{tabular}{|c|c|c|}
\hline Work Aspect & $\underline{N}$ & $\underline{I}^{\mathrm{a}}$ \\
\hline Fercelved Soctal Value of Work & 155 & $.46 * * *$ \\
\hline Sense of Accomplishment & 164 & $.44 * * *$ \\
\hline \multicolumn{3}{|l|}{ Agency Goals: } \\
\hline Worthiness & 152 & $.43^{* * *}$ \\
\hline Attainability & 152 & $.40 * * *$ \\
\hline Clarity & 158 & $.40^{* * *}$ \\
\hline Utilization of Skills & 158 & $.38 * * *$ \\
\hline Degree of Visible Impact on Agency & 164 & $.31 * * *$ \\
\hline Amblgutty of Role Expectations & 163 & $-.26 * * *$ \\
\hline Adequacy of Communtcation in Agency & 157 & $.22 * *$ \\
\hline Autonomy & 163 & $.19 *$ \\
\hline Role Overload: Too Much Work & 163 & $-.16 *$ \\
\hline Knowledge of Job Dutles & 164 & .15 \\
\hline Conflict in Role Expectations & 163 &.- .14 \\
\hline Role Overload: InsuffIcient THme & 164 & -.05 \\
\hline Amount of Contact with Clients & 154 & -.01 \\
\hline Salary & 150 & .00 \\
\hline
\end{tabular}

\footnotetext{
aproduct-moment correlation with score on Work Scale of JDI

"p $<.05$

$* \underline{p}<.01$

$* * * \mathrm{p}<.001$
}

agency, were significantly correlated with level of work satisfaction (see Table 3).

The three other frequently cited sources of satisfaction or dissatisfaction were co-workers, autonomy, and learning and personal development. The data in Table 2 suggest that co-workers and amount of learning in the job tend to be sources of satisfaction more often than dissatisfaction, although autonomy is more problematic. Many staff like their work precisely because it is high in autonomy, but just as many staff cite lack of autonomy as a major frustration. Perhaps in a hierarchical, bureaucratic organization, where some enjoy more power and autonomy than others, this finding should be expected. 


\section{DISCUSSION}

The results of this study suggest that work in many community mental health programs is unusually frustrating and dissatisfying for staff. If the trends emerging from our sample exist in other programs in other parts of the country, community mental health administrators will experience increasing difficulty in recruiting and retaining effective staff members. Pressure for staff unionization in these programs also will increase, internal conflict and dissension will occur more frequently, and ultimately the quality of service will deteriorate. These problems may already be occurring in many programs.

However, the findings also suggest where and how administrators might intervene. They suggest that, in general, staff are relatively more dissatisfied with the content of their jobs than with their co-workers or supervision. (Of course, in some programs there could be serious problems in the domains of co-workers or supervision as well. The exact extent and nature of the problem always will vary with the program.) The results also suggest that factors influencing the staff's sense of accomplishment are particularly salient.

One important aspect of the community mental health movement has been that mental health professionals are being asked to assume new roles in mental health consultation and community action. As Reiff (1966) noted, most mental health professionals have not received adequate training and supervision in these new roles and are painfully aware of their own inadequacies in these areas. Thus it is not surprising that in community mental health the sense of competence and accomplishment has become the most important and problematic aspect of the work experience for the typical staff member.

To increase the sense of accomplishment in community mental health work, more staff development would seem to be indicated. Good in-service training, especially in those areas where the staff feels less confident (mental health consultation and community organization), could help improve both morale and performance. Supervisors also should be included in these professional development programs. Many staff members told us that not only did they feel less sure of themselves in the new areas of professional work, their supervisors also are less knowledgeable and thus less helpful in these new areas.

Our findings also suggest the influence of organizational quality on job satisfaction. Especially for mental health consultation and other new services, many staff members feel that their program's expectations and objectives are less well defined, contributing to ambiguity, conflict, frustration, and lower job satisfaction. Thus another recommendation suggested by our research is that administrators devote some attention to clarifying goals, objectives, and responsibilities in areas such as mental health consultation and education where high ambiguity interferes with staff performance.

These findings also point to the critical need for research and development 
activities in areas where the present theories and technologies are weak. The development of assessment tools such as the Consultation Readiness Scale (Cherniss, 1978), and continued refinement of ambiguous areas of consultation theory (Cherniss, 1976), can provide staff in community mental health with more sophisticated intervention methodologies which will promote a greater sense of competence and accomplishment in their work.

Currently there is much national interest in the quality of work and the design of jobs in a variety of occupations. Many exciting experiments in the redesign of jobs are being conducted (for example, Work in America, 1973). However, external factors may limit the extent to. which jobs in community mental health centers can be redesigned in some cases. For instance, when federal, state, and local governments reduce real funding of programs at the same time that the incidence of emotional disturbance in the community increases due to economic hardship, staff case loads probably will increase. Such increases mean that staff members have less time and energy to give each individual client, which ultimately will interfere with one's sense of accomplishment. However, it still is true that staff and administrators can, and should, increase job satisfaction by redesigning jobs; for it usually will be easier to change jobs than to change the world's economy or federal funding priorities.

\section{REFERENCES}

Cherniss, C. Preentry issues in consultation. American Journal of Community Psychology, 1976, 4, 13-24.

Cherniss, $C$. The consultation readiness scale: An attempt to improve consultation practice. American Journal of Community Psychology, 1978, 6, 15-21.

Dunn, N. Mental health agency fares well in audit. Ann Arbor News, February 26, 1976, p. 3.

Frank, J. Persuasion and healing. Baltimore, Md.: Johns Hopkins University Press, 1973.

Mills, C. W. White collar. New York: Oxford University Press, 1951.

Oppenheimer, M. The unionization of the professional. Social Policy, 1975, 5, 34-40.

Reiff, R. Mental health manpower and institutional change. American Psychologist, 1966, 21, $540-548$.

Sarason, S. B. The psychological sense of community: Prospects for a community psychology. San Francisco, Calif.: Jossey-Bass, 1974.

Sarata, B. P. V. Job satisfactions of individuals working with the mentally retarded. Unpublished doctoral dissertation, Yale University, 1972.

Schwartz, M. S., \& Will, G. T. Intervention and change on a mental hospital ward. In W. G. Bennis, K. D. Benne, \& R. Chinn (Eds.), The planning of change. New York: Holt, Rinehart \& Winston, 1961.

Smith, P. C., Kendall, L. M., \& Hulin, C. L. The measurement of satisfaction in work and retirement. Chicago: Rand McNally, 1969.

Stotland, E., \& Kobler, A. L. Life and death of a mental hospital. Seattle, Wash.: University of Washington Press, 1965.

Work in America. Report of a task force to the secretary of HEW. Cambridge, Mass.: MIT Press, 1973. 